УДК 582.623.2

\title{
ИССЛЕДОВАНИЕ СОДЕРЖАНИЯ ФЛАВОНОИДОВ И АНТОЦИАНОВ В СПЕЛЫХ ПЛОДАХ БУЗИНЫ
}

\author{
(C) М.Л. Татвидз $e^{I^{*}}$, А.Г. Каландия ${ }^{2}$ \\ ${ }^{1}$ Кутаисский государственный университет им. А. Церетели, ул. Царицы \\ Тамары, 59, Кутаиси, 4600 (Грузия), e-mail:m.tatvidze@yahoo.com \\ ${ }^{2}$ Батумский государственный университет им. Шота Руставели, \\ ул. Ниношвили, 35, Батуми, 6010 (Грузия)
}

Методом жидкостной хроматографии исследованы плоды бузины (Sambucus nigra L.), распространенной в высокогорных районах Грузии, на наличие фенольных соединений. Определен количественный и качественный состав флавоноидных гликозидов и антоцианов. Установлено, что спелый плод бузины содержит флавоноидных гликозидов 289 мг/кг и антоцианов 1110 мг/кг.

Ключевые слова: бузина, Sambucus nigra L., жидкостная хроматография, антоцианы, флавоноиды.

Растения, богатые флавоноидами и антоцианами, широко используются в терапевтических целях. Общеизвестна сильная антиоксидантная активность этих соединений. Препараты и биологически активные добавки, содержащие флавоноиды и антоцианы, применяются при лечении воспалительных, язвенных, сосудистых, опухолевых и многих других заболеваний. Исследования в этом направлении ведутся уже многие годы, хотя полностью изучены далеко не все виды растительного сырья.

Большинство дикорастущих растений содержат огромное количество весьма полезных биологически активных веществ. В экологически чистых горных районах Грузии много дикорастущей бузины (Sambucus nigra L), цветки и плоды которой широко применяются в современной народной медицине.

Цель нашей работы - изучение количественного и качественного содержания фенольных соединений, в частности флавоноидных гликозидов и антоцианов, в спелых плодах бузины, собранных в горах Аджарии и Имеретии.

Для приготовления образца на 5-10 г сырого плода бузины добавляется 100 мл этанола, а также определенное количество 5\%-й муравьиной кислоты. Для лучшей экстракции антоцианов оптимальная температура выдержки $15-18{ }^{\circ} \mathrm{C}$.

Качественный анализ образца проводили на градиентном хроматографе Waters (USA), uv/visible Detector 2489, Binary HPLC Pump1525. Хроматографический столб Symmetry C18, детектирование при 510 нм. Подвижная фаза - 5\%-я муравьиная кислота (А) и этанол (В), линейный градиент, скорость растворения 1 мл/мин, количество исследуемого образца $20 \mu 1$.

Методом хроматографии доказано, что плоды бузины содержат не менее 10 соединений, которые детектируются при 370 нм (рис. 1). Среди них четыре доминирующих пика (время удерживания 22,119 мин, 22,5\% общей площади, предположительно рутин).

При 510 нм предположительно детектируется гликозид цианидин (время удерживания 10,338 мин, общая площадь $78,42 \%$ ) (рис. 2).

Татвидзе Мальвина - докторант кафедры химических технологий лекарственных препаратов,

e-mail: m.tatvidze@yahoo.com

Каландия Алеко - профессор кафедры химических технологий, доктор технических наук,

e-mail: aleko.kalandia@gmail.com

\footnotetext{
* Автор, с которым следует вести переписку.
}

Из флавоноидных гликозидов идентифицированы кверцетин-3-О-гликозид и кверцетин3-Орутинозид. Общее содержание фенольных соединений в плодах бузины представлено в таблице. 


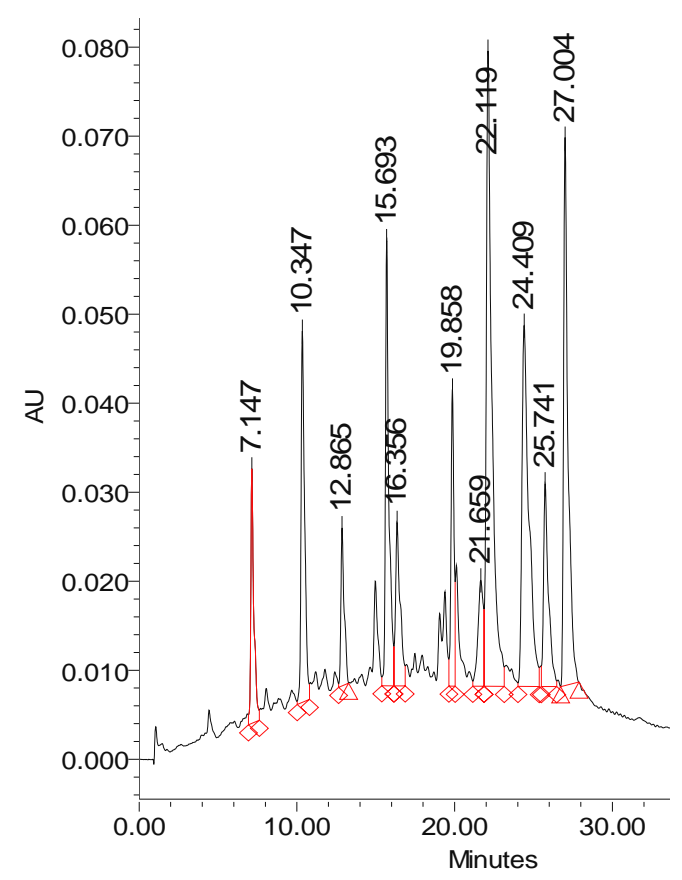

Рис. 1. Жидкостная хроматография флавоноидных гликозидов плодов бузины. Детектирование при $370 \mathrm{HM}$

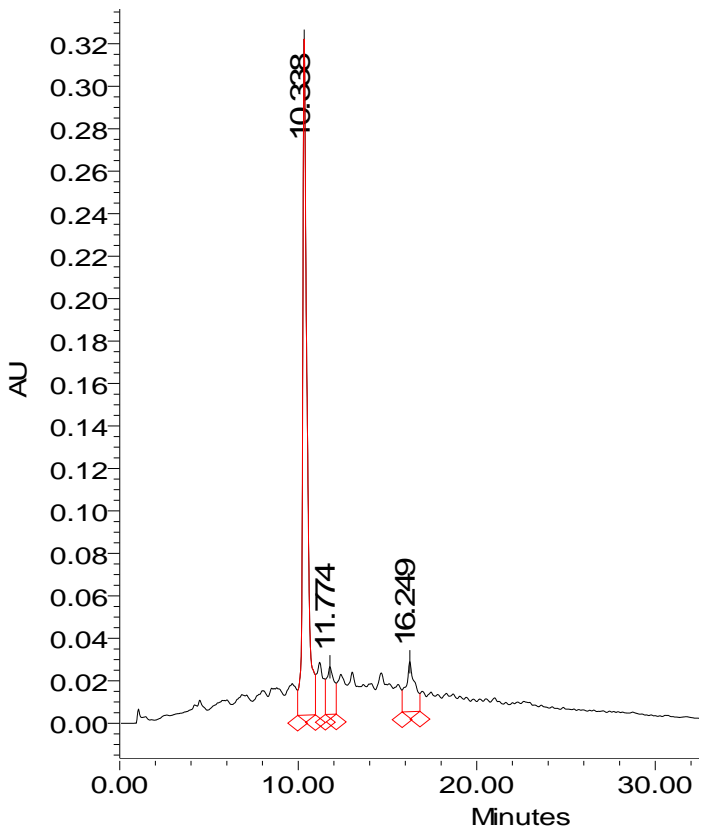

Рис. 2. Жидкостная хроматография антоцианов плодов бузины. Детектирование при 510 нм

Содержание фенольных соединений в плодах бузины

\begin{tabular}{|c|c|c|c|c|c|}
\hline & \multirow{2}{*}{ Образец } & \multicolumn{4}{|c|}{ Фенольные соединения мг/кг } \\
\hline & & антоцианы & лейкоантоцианы & катехины & флавоноиды \\
\hline $\begin{array}{c}\text { Сырые плоды } \\
\text { бузины }\end{array}$ & $\begin{array}{l}\text { Перерасчет на сырую массу } \\
\text { Перерасчет на сухую массу }\end{array}$ & $\begin{array}{c}244,32 \\
1110,54\end{array}$ & $\begin{array}{c}74,2 \\
337,27\end{array}$ & $\begin{array}{c}61,4 \\
279,09\end{array}$ & $\begin{array}{c}78 \\
289\end{array}$ \\
\hline $\begin{array}{l}\text { Сухие плоды } \\
\text { бузины }\end{array}$ & $\begin{array}{l}\text { Перерасчет на сырую массу } \\
\text { Перерасчет на сухую массу }\end{array}$ & $\begin{array}{l}780,7 \\
950,3\end{array}$ & $\begin{array}{l}235,2 \\
268,5\end{array}$ & $\begin{array}{l}197,2 \\
210,2\end{array}$ & $\begin{array}{c}209 \\
220,5\end{array}$ \\
\hline
\end{tabular}

\section{Заключение}

Плоды бузины богаты фенольными соединениями. Из флавоноидных гликозидов идентифицированы кверцетин-3-О-гликозид и кверцетин-3-О-рутинозид, количество которых при переработке плодов бузины сохраняется.

Среди фенольных соединений доминируют природные антоцианы (1110,54 мг/кг и больше). Следует отметить, что количественный состав антоцианов также практически не меняется в процессе сушки плодов бузины.

Известно, что в южных и высокогорных районах под влиянием света и тепла увеличивается содержание флавоноидов. Этот фактор делает исследуемый нами продукт бузины особенно ценным. Добыча и технологическая обработка плодов бузины довольно легка и несоизмеримо дешевле обходится производству по сравнению с другим растительным сырьем.

\section{Список литературь}

1. Nakatani N., Kikuzaki H., Hikida J., Ohba M., Inami O., Tamura I. Acylated anthocyanins from fruits of Sambucus canadensis // Phytochemistry. 1995. Vol. 38, N3. Pp. 755-757.

2. Abuja P.M., Murkovic M., Pfannhauser W. Antioxidant and prooxidant activities of elderberry (Sambucus nigra) extract in low-density lipoprotein oxidation // Journal of Agricultural and Food Chemistry. 1998. Vol. 46, N10, Pp. 4091-4096.

3. Rice-Evans C.A., Miller N.J., Papanga G. Structure-antioxidant activity relationships of flavonoids and phenolic acids // Free Radical Biology and Medicine. 1996. Vol. 20, N7. Pp. 933-956. 
Tatvidze $M .^{I^{*}}$, Kalandia $A .^{2}$ STUDY OF THE CONTENT OF FLAVONOIDS AND ANTHOCYANINS IN RIPE FRUITS OF SAMBUCUS NIGRA L.

${ }^{I}$ Kutaisi A. Tsereteli State University, Tamar Mepe st., 59, Kutaisi, 4600 (Georgia), e-mail: m.tatvidze@yahoo.com

${ }^{2}$ Batumi Shota Rustaveli State University, Ninoshvili st., 35, Batumi, 6010 (Georgia)

Using liquid chromatography studied fruit elderberry (Sambucus nigra L), ubiquitous in the highlands of Georgia for the presence of phenolic compounds. The quantitative and qualitative composition of flavonoid glycosides and anthocyanins. Found that ripe fruit of elderberry contains flavonoid glycosides $-289 \mathrm{mg} / \mathrm{kg}$ and anthocyanins $-1110 \mathrm{mg} / \mathrm{kg}$.

Keywords: Sambucus nigra L., liquid chromatography, anthocyanins, flavonoids.

\section{References}

1. Nakatani N., Kikuzaki H., Hikida J., Ohba M., Inami O., Tamura I. Phytochemistry, 1995, vol. 38, no. 3, pp. $755-757$.

2. Abuja P.M., Murkovic M., Pfannhauser W. Journal of Agricultural and Food Chemistry, 1998, vol. 46, no. 10, pp. 4091-4096.

3. Rice-Evans C.A., Miller N.J., Papanga G. Free Radical Biology and Medicine, 1996, vol. 20, no. 7, pp. $933-956$.

Received July 31, 2012

\footnotetext{
* Corresponding author.
} 
